Check for updates

Cite this: Chem. Sci., 2019, 10, 8246

๑ All publication charges for this article have been paid for by the Royal Society of Chemistry

Received 2nd June 2019

Accepted 16th July 2019

DOI: $10.1039 / c 9 s c 02674 f$

rsc.li/chemical-science

\section{A cruciform phthalocyanine pentad-based NIR-II photothermal agent for highly efficient tumor ablation $\uparrow$}

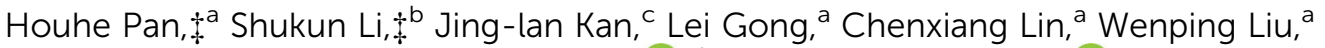 \\ Dongdong $\mathrm{Qi}^{\mathrm{a}}{ }^{\mathrm{K}}$ Kang Wang, ${ }^{\mathrm{a}}$ Xuehai Yan (D) ${ }^{* \mathrm{~b}}$ and Jianzhuang Jiang (D) *a
}

\begin{abstract}
Photothermal therapy in the second near-infrared window (NIR-II, 1000-1700 nm) exhibits a significant advantage over the first near-infrared window (NIR-I, 650-950 nm) in terms of both maximum permissible exposure (MPE) and penetration depth. However, the thus far reported NIR-II photothermal agents (PTAs) have been focused just on inorganic semiconducting and organic polymeric semiconducting nanoparticles. Herein a novel cruciform phthalocyanine pentad was designed, synthesized, and characterized for the first time. The water-soluble nanoparticles $\left(\mathrm{Zn}_{4}-\mathrm{H}_{2} \mathrm{Pc} / \mathrm{DP} \mathrm{NPs}\right)$ assembled from this single molecular material with the help of DSPE-PEG $2000-\mathrm{OCH}_{3}$ exhibit characteristic absorption in the NIR-II region at $1064 \mathrm{~nm}$ with a large extinction coefficient of $52 \mathrm{~L} \mathrm{~g}^{-1}$ $\mathrm{cm}^{-1}$, high photothermal conversion efficiency of $58.3 \%$, and intense photoacoustic signal. Moreover, both in vitro and in vivo studies reveal the good biocompatibility and notable tumor ablation ability of $\mathrm{Zn}_{4}-\mathrm{H}_{2} \mathrm{Pc} / \mathrm{DP}$ NPs under $1064 \mathrm{~nm}$ laser irradiation. Theoretical density functional theory calculations interpret the two-dimensional compressional wave energy-dissipation pathway over the broad saddle curved framework of the cruciform conjugated phthalocyanine pentad, rationalizing the efficient photothermal properties of corresponding $\mathrm{Zn}_{4}-\mathrm{H}_{2} \mathrm{Pc} / \mathrm{DP}$ NPs in the NIR-II window.
\end{abstract}

\section{Introduction}

Quite lately, photothermal therapy ${ }^{1-4}$ (PTT) in the second nearinfrared (NIR-II, 1000-1700 $\mathrm{nm}$ ) window has aroused researchers' attention due to its significant advantage over the first near-infrared window (NIR-I, 650-950 nm) in terms of both maximum permissible exposure (MPE) and penetration depth. ${ }^{5,6}$ Intensive studies have resulted in reports of a number of inorganic semiconducting and organic polymeric semiconducting material-based photothermal agents (PTAs) in the NIR-II region, such as B-TiO ${ }_{2-x}-\mathrm{PEG},{ }^{7}$ Sb-doped $\mathrm{SnO}_{2},{ }^{8} \mathrm{Nb}_{2} \mathrm{C}$ NSs, P1RGD NPs, ${ }^{10} \mathrm{SPN}_{\mathrm{I}-\mathrm{II}}{ }^{11}$ and TBDOPV-DT. ${ }^{12}$ However, molecular material-based PTAs for the NIR-II window PTT with a well-defined chemical composition and molecular structure still remain unreported due to the difficulty in developing

\footnotetext{
${ }^{a}$ Beijing Key Laboratory for Science and Application of Functional Molecular and Crystalline Materials, Department of Chemistry, University of Science and Technology Beijing, Beijing 100083, China. E-mail: jianzhuang@ustb.edu.cn

${ }^{b}$ State Key Laboratory of Biochemical Engineering, Institute of Process Engineering, Chinese Academy of Sciences, Beijing 100190, China. E-mail: yanxh@ipe.ac.cn

'Key Laboratory of Molecular and Nano Probes, Ministry of Education, Shandong Normal University, Jinan 250014, China

$\dagger$ Electronic supplementary information (ESI) available: Experimental materials and methods, characterization data, and additional data. See DOI: 10.1039/c9sc02674f

$\$$ These authors contributed equally to this work.
}

molecular compounds with an absorption band beyond 1000 $\mathrm{nm}$, to the best of our knowledge.

Phthalocyanines (Pcs) are one of the most promising second generation photosensitizers due to their relatively long absorption wavelengths $\left(\lambda_{\max }>650 \mathrm{~nm}\right)$, high extinction coefficients $\left(\varepsilon_{\max }>\right.$ $10^{5} \mathrm{~L} \mathrm{~mol}^{-1} \mathrm{~cm}^{-1}$ ), and tunable photophysical and photochemical properties through facile chemical modifications. ${ }^{13-15}$ In particular, fusing monomeric phthalocyanine units into conjugated dimeric and trimeric frameworks has been revealed to result in a significant red-shift in the intense $\mathrm{Q}$ band adsorption of resulting molecular materials. ${ }^{16,17}$ Further expansion in the oligomeric Pc-conjugated system with the number of Pc units more than three is therefore expected to afford a suitable single molecular material with an intense absorption band beyond $1000 \mathrm{~nm}$, with promising photothermal properties in the NIR-II window.

Herein we report the development of the first organic molecular material-based photothermal agent $\mathrm{Zn}_{4}-\mathrm{H}_{2} \mathrm{Pc} / \mathrm{DP}$ NPs for NIR-II window tumor photothermal therapy. Firstly, a novel cruciform conjugated phthalocyanine pentad $\mathrm{Zn}_{4}{ }^{-}$ $\mathrm{H}_{2}\left[\mathrm{Pc}\left(\mathrm{OC}_{12} \mathrm{H}_{17}\right)_{24}\right]$ (1) was designed, synthesized, and characterized. The water-soluble nanoparticles assembled from 1 with the help of DSPE- $\mathrm{PEG}_{2000}-\mathrm{OCH}_{3}\left(\mathrm{Zn}_{4}-\mathrm{H}_{2} \mathrm{Pc} / \mathrm{DP} \mathrm{NPs}\right)$ exhibit characteristic absorption in the NIR-II region at $1064 \mathrm{~nm}$ with a high extinction coefficient of $52 \mathrm{~L} \mathrm{~g}^{-1} \mathrm{~cm}^{-1}$, high physiological and photothermal stability, and high photothermal conversion efficiency of 58.3\%. Moreover, strong photoacoustic 
signals were observed for $\mathrm{Zn}_{4}-\mathrm{H}_{2} \mathrm{Pc} / \mathrm{DP}$ NPs, which provided guidance for choosing the optimal time for PTT. In particular, both in vitro and in vivo studies reveal the good biocompatibility and notable tumor ablation ability of $\mathrm{Zn}_{4}-\mathrm{H}_{2} \mathrm{Pc} / \mathrm{DP}$ NPs in the second NIR window. Theoretical calculations by density functional theory interpret the electronic structure and especially the two-dimensional compressional wave fluttering energydissipation pathway of $\mathbf{1}$, rationalizing the efficient photothermal properties of $\mathrm{Zn}_{4}-\mathrm{H}_{2} \mathrm{Pc} / \mathrm{DP}$ NPs in the NIR-II window.

At the end of this section, it is worth noting that for the purpose of enhancing the photothermal conversion efficiency, scientists usually tried to reduce the radiative transition probability as much as possible generally via photoinduced electron transfer, fluorescence resonance energy transfer, and/or molecular stacking. ${ }^{18,19}$ In good contrast, for two-dimensional conjugated materials, a new type of smooth energy-dissipation pathway, i.e. two-dimensional compressional wave fluttering over the broad framework, was revealed to be employed to directly and effectively promote the nonradiative decay pathway, realizing intrinsic molecular energy degradation..$^{20}$ As a consequence, the corresponding cruciform conjugated phthalocyanine pentad compound, $\mathrm{Zn}_{4^{-}}$ $\mathrm{H}_{2}\left[\mathrm{Pc}\left(\mathrm{OC}_{12} \mathrm{H}_{17}\right)_{24}\right]$ (1), with a large conjugated framework was fabricated in the present case. In addition, it must be pointed out that the free rotation of peripheral substituents in the molecules of $\mathbf{1}$ as well as the breathing inter-molecular fibrillation of the assembled nanostructures also helps to contribute to convert NIRII light to heat efficiently for $\mathrm{Zn}_{4}-\mathrm{H}_{2} \mathrm{Pc} / \mathrm{DP}$ NPs.

\section{Results and discussion}

\section{Synthesis and characterization of $\mathrm{Zn}_{4}-\mathrm{H}_{2}\left[\mathrm{Pc}\left(\mathrm{OC}_{12} \mathrm{H}_{17}\right)_{24}\right]$ (1)}

Binuclear and trinuclear conjugated phthalocyanine frameworks with red-shifted Q-band absorption in the NIR-I region and enhanced extinction coefficients have been developed and characterized. ${ }^{16,17}$ This inspires us to fabricate a further enlarged Pc-based oligomeric conjugated system with an intense absorption band located in the second near-infrared window, beyond $1000 \mathrm{~nm}$. As illustrated in Scheme $\mathrm{S} 1, \uparrow$ the cruciform conjugated phthalocyanine pentad $\mathrm{Zn}_{4}$ $\mathrm{H}_{2}\left[\mathrm{Pc}\left(\mathrm{OC}_{12} \mathrm{H}_{17}\right)_{24}\right]$ (1) was synthesized for the first time. As expected, compound $\mathbf{1}$ indeed exhibited a narrow and intense absorption band at $1040 \mathrm{~nm}$ in $\mathrm{CH}_{2} \mathrm{Cl}_{2}$, located within the NIRII region $\left(\lambda_{\max }=1040 \mathrm{~nm}, \varepsilon=5.8 \times 10^{5} \mathrm{M}^{-1} \mathrm{~cm}^{-1}\right)$. In particular, this single molecular compound displays weak fluorescence in $\mathrm{CH}_{2} \mathrm{Cl}_{2}\left(\lambda_{\text {ex }}=880 \mathrm{~nm}, \lambda_{\mathrm{em}}=1081 \mathrm{~nm}, \Phi_{\mathrm{f}}=2.8 \%\right.$, Scheme $1 \mathrm{~b}$ ) and extremely poor singlet oxygen yield. As a total result, this novel cruciform phthalocyanine pentad shows great potential as a good PTA in the NIR-II window.

\section{Synthesis and characterization of $\mathrm{Zn}_{4}-\mathrm{H}_{2} \mathrm{Pc} / \mathrm{DP}$ NPs}

To investigate the photothermal properties of the phthalocyanine pentad in aqueous solution, the $\mathrm{Zn}_{4}-\mathrm{H}_{2} \mathrm{Pc} / \mathrm{DP}$ NPs were prepared by mixing $\mathrm{Zn}_{4}-\mathrm{H}_{2}\left[\mathrm{Pc}\left(\mathrm{OC}_{12} \mathrm{H}_{17}\right)_{24}\right]$ (1) DMAE/THF solution with DSPE- $\mathrm{PEG}_{2000}-\mathrm{OCH}_{3}$ aqueous solution, dialyzing, concentrating, and then re-dispersing to different concentrations or solvents. As can be seen in Scheme $1 \mathrm{~b}$, the UV-vis-NIR absorption and fluorescence emission spectra of $\mathrm{Zn}_{4}-\mathrm{H}_{2} \mathrm{Pc} / \mathrm{DP}$ NPs in water were recorded. Compared to the $\mathrm{Q}$ band of $\mathrm{Zn}_{4}-\mathrm{H}_{2}\left[\mathrm{Pc}\left(\mathrm{OC}_{12} \mathrm{H}_{17}\right)_{24}\right]$ (1) in $\mathrm{CH}_{2} \mathrm{Cl}_{2}$, the obtained $\mathrm{Zn}_{4}-\mathrm{H}_{2} \mathrm{Pc} / \mathrm{DP}$ NPs show a slightly red-shifted Q band at 1048 $\mathrm{nm}$ with a lower but still intensive extinction coefficient $(\varepsilon=3.7$ $\times 10^{5} \mathrm{M}^{-1} \mathrm{~cm}^{-1}$, which may be attributed to the $J$-aggregates from the self-assembly of phthalocyanine molecules. ${ }^{21,22}$ This also led to the red-shifted fluorescent emission $\left(\lambda_{\text {ex }}=880 \mathrm{~nm}\right.$, $\lambda_{\mathrm{em}}=1108 \mathrm{~nm}$ ) and significantly decreased fluorescence
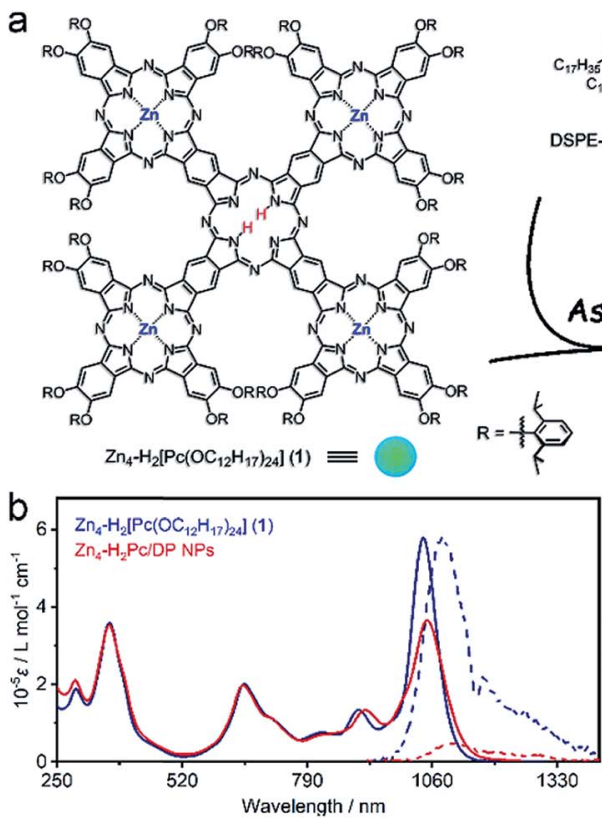
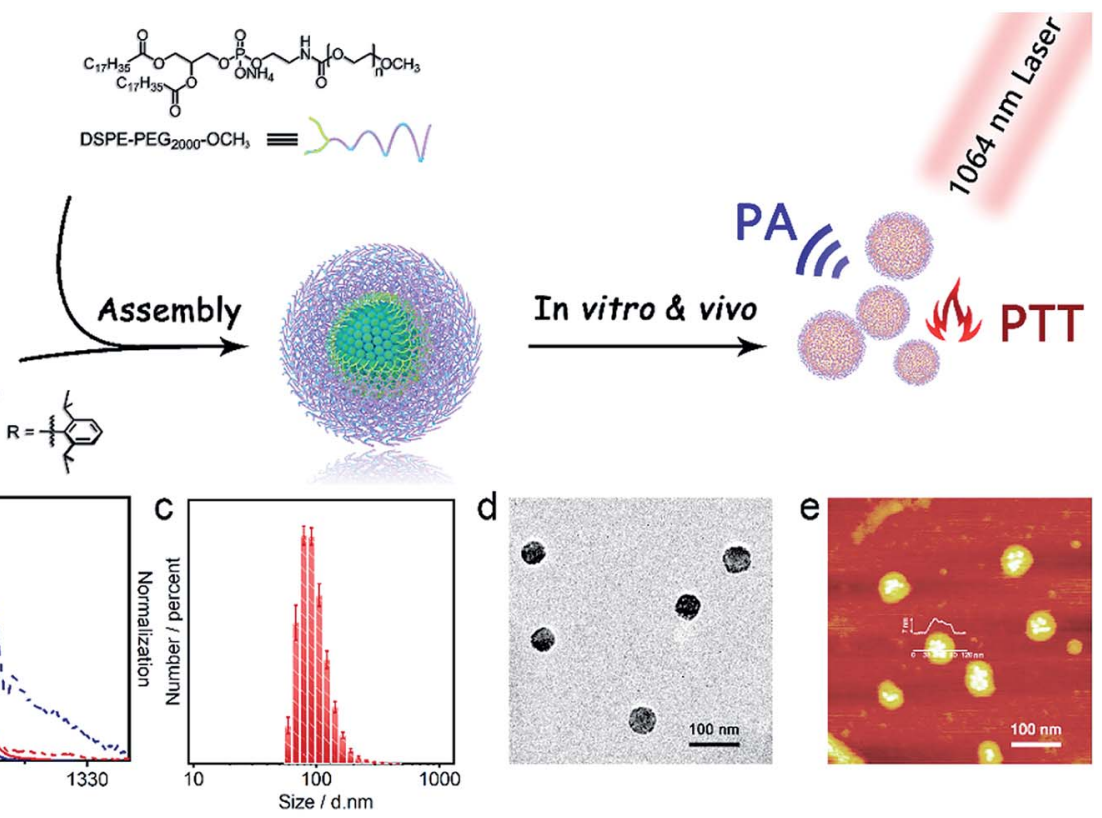

Scheme 1 (a) Illustration of $\mathrm{Zn}_{4}-\mathrm{H}_{2} \mathrm{Pc} / \mathrm{DP}$ NP fabrication for photothermal therapy and photoacoustic imaging. (b) UV-vis-NIR absorption and fluorescence emission spectra of $\mathrm{Zn}_{4}-\mathrm{H}_{2}\left[\mathrm{Pc}\left(\mathrm{OC}_{12} \mathrm{H}_{17}\right)_{24}\right]$ (1) in $\mathrm{CH}_{2} \mathrm{Cl}_{2}$ and $\mathrm{Zn}_{4}-\mathrm{H}_{2} \mathrm{Pc} / \mathrm{DP}$ NPs in water, respectively. (c) DLS profile, (d) TEM, and (e) AFM images of $\mathrm{Zn}_{4}-\mathrm{H}_{2} \mathrm{Pc} / \mathrm{DP}$ NPs. 
quantum yield $\left(Q_{\mathrm{f}}=0.2 \%\right.$ ) for $\mathrm{Zn}_{4}-\mathrm{H}_{2} \mathrm{Pc} / \mathrm{DP}$ NPs. The hydrodynamic diameter of $\mathrm{Zn}_{4}-\mathrm{H}_{2} \mathrm{Pc} / \mathrm{DP}$ NPs was found to be approximately $85 \mathrm{~nm}$ (Scheme 1c) via dynamic light scattering (DLS) analysis. Transmission electron microscopy (TEM) and atomic force microscopy (AFM) images also revealed the spherical structure of these nanoparticles with uniform morphology and size with diameters of 40-70 $\mathrm{nm}$ as shown in Scheme $1 \mathrm{~d}$ and e. The suitable $\zeta$ potential of $\mathrm{Zn}_{4}-\mathrm{H}_{2} \mathrm{Pc} / \mathrm{DP}$ NPs [-31 mV, Fig. S6†] and hydrated diameter of $\mathrm{Zn}_{4}-\mathrm{H}_{2} \mathrm{Pc} / \mathrm{DP}$ NPs enable their easy accumulation in the tumor regions via the enhanced permeability and retention effect. ${ }^{23}$ Additionally, the UV-vis-NIR absorption and size distribution for various concentrations of $\mathrm{Zn}_{4}-\mathrm{H}_{2} \mathrm{Pc} / \mathrm{DP}$ NPs prepared were also tested, Fig. S7-S9. $\dagger$ All these results revealed the high physiological stability of $\mathrm{Zn}_{4}-\mathrm{H}_{2} \mathrm{Pc} / \mathrm{DP}$ NPs, even for those lasting for 73 days, ensuring their promising biomedical applications.

\section{Photothermal properties and photoacoustic imaging performance}

The mass extinction coefficient of $\mathrm{Zn}_{4}-\mathrm{H}_{2} \mathrm{Pc} / \mathrm{DP}$ NPs at $1064 \mathrm{~nm}$ is $52 \mathrm{~L} \mathrm{~g}^{-1} \mathrm{~cm}^{-1}$, Scheme $1 \mathrm{~b}$, higher than those of most previously reported NIR-II organic or inorganic PTAs. ${ }^{7-12}$ This indicates the high efficiency of $\mathrm{Zn}_{4}-\mathrm{H}_{2} \mathrm{Pc} / \mathrm{DP}$ NPs in transforming photons into heat in terms of material weight. To directly evaluate the photothermal performance of $\mathrm{Zn}_{4}-\mathrm{H}_{2} \mathrm{Pc} / \mathrm{DP}$ NPs, we measured the concentration-dependent and laser powerdependent photothermal behaviour of the nanoparticles, Fig. 1a and b. After $10 \mathrm{~min}$ irradiation at $0.9 \mathrm{~W} \mathrm{~cm}^{-2}$, the temperature of $\mathrm{Zn}_{4}-\mathrm{H}_{2} \mathrm{Pc} / \mathrm{DP}$ NPs $(27 \mathrm{ppm})$ increased by $24.0^{\circ} \mathrm{C}$, see Fig. 1a, which is higher than that for pure water $\left(5.2^{\circ} \mathrm{C}\right)$. Subsequently, according to the data obtained, Fig. 1c, the photothermal conversion efficiency $(\eta)$ was calculated to be $58.3 \%,{ }^{21}$ which is higher than that of most previously reported NIR-II organic or inorganic PTAs, such as B-TiO ${ }_{2-x}(39.8 \%),{ }^{7}$ $\mathrm{Sb}_{0.2}-\mathrm{SnO}_{2}(48.3 \%),{ }^{8} \mathrm{Nb}_{2} \mathrm{C}$ NSs $(45.6 \%),{ }^{9}$ P1RGD NPs $(30.1 \%),{ }^{10}$ and $\mathrm{SPN}_{\mathrm{I}-\mathrm{II}}(43.4 \%) .{ }^{11} \mathrm{Next}$, we assessed the photothermal stability of $\mathrm{Zn}_{4}-\mathrm{H}_{2} \mathrm{Pc} / \mathrm{DP}$ NPs. The variation in the temperature of the $\mathrm{Zn}_{4}-\mathrm{H}_{2} \mathrm{Pc} / \mathrm{DP} \mathrm{NP}$ solution was monitored, Fig. 1d, and no obvious deterioration after seven cycles of irradiation was observed.

We also explored the tissue-penetration photothermal ability through chicken breast muscles of varying thickness $(0,1$, and 4 $\mathrm{mm}$ ) using $\mathrm{Zn}_{4}-\mathrm{H}_{2} \mathrm{Pc} / \mathrm{DP}$ NPs under $1064 \mathrm{~nm}$ laser irradiation. As illustrated in Fig. 1e and $S 11, \dagger$ after 6 min irradiation, the

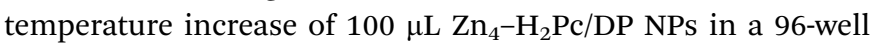
plate can rapidly reach $56.6{ }^{\circ} \mathrm{C}$ without a tissue covering, while that of NPs under $4 \mathrm{~mm}$ chicken tissue also showed an increase of $15.2{ }^{\circ} \mathrm{C}$ with no significant heating (below $3{ }^{\circ} \mathrm{C}$ ) recorded for the tissue, which exceeded the required temperature rise $\left(13^{\circ} \mathrm{C}\right)$ to ablate tumor cells in living mice. ${ }^{11}$

Photoacoustic (PA) imaging is a new emerging biomedical imaging technology based on light excitation and ultrasonic emission, which is often accompanied during the photothermal transformation. As a consequence, in this case the PA signals for $\mathrm{Zn}_{4}-\mathrm{H}_{2} \mathrm{Pc} / \mathrm{DP}$ NPs in the agarose gel phantom at various concentrations were recorded from 700 to $960 \mathrm{~nm}$. As can be seen in Fig. If and S12, $\uparrow$ the PA signal intensity reached the top value at around $900 \mathrm{~nm}$ and got enhanced in an almost linear manner along with the increase in the concentration of $\mathrm{Zn}_{4^{-}}$
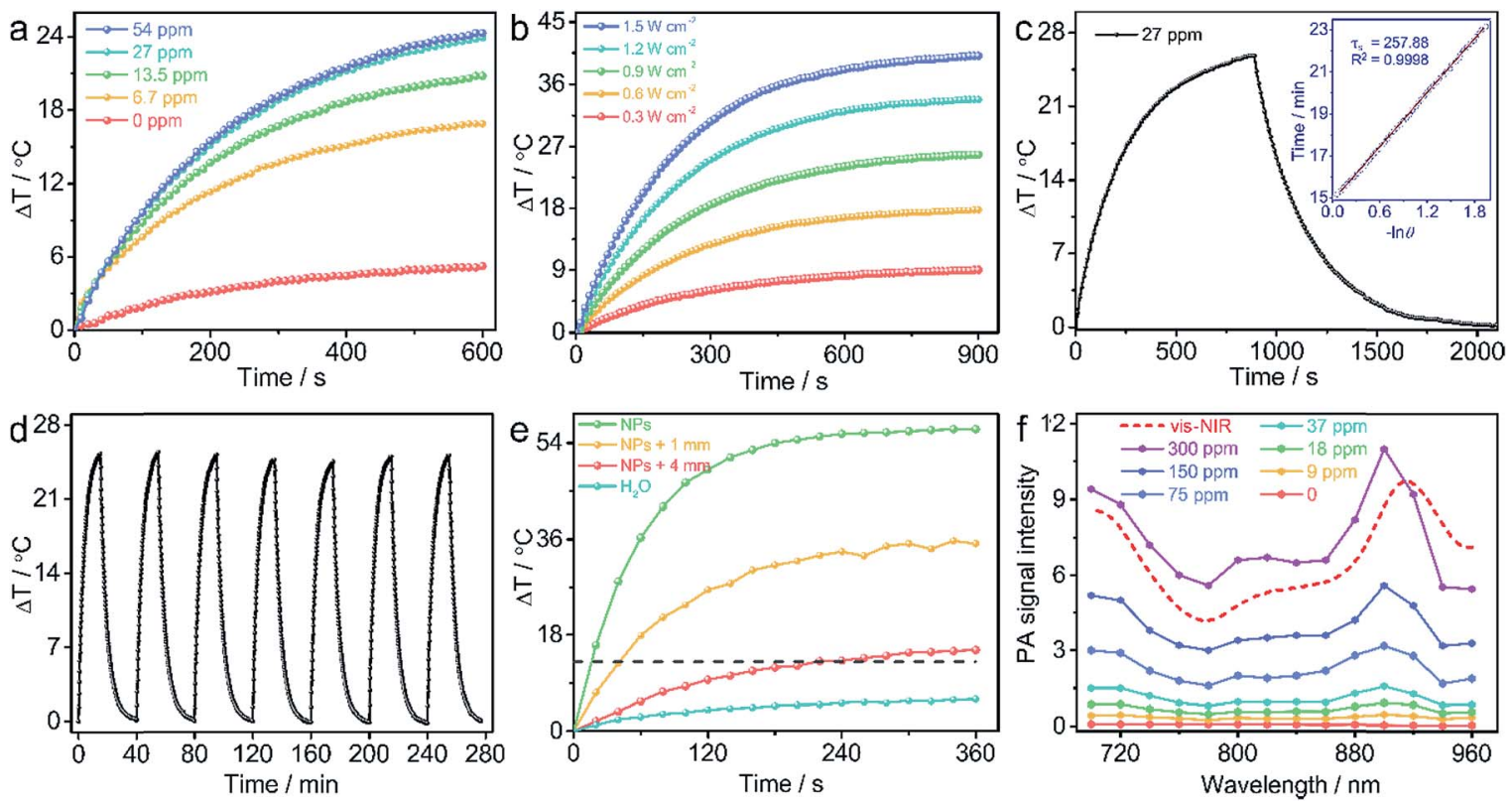

Fig. 1 Temperature change curves of $\mathrm{Zn}_{4}-\mathrm{H}_{2} \mathrm{Pc} / \mathrm{DP}$ NPs exposed to the $1064 \mathrm{~nm}$ laser (a) at various concentrations $\left(0.9 \mathrm{~W} \mathrm{~cm}^{-2}, 10 \mathrm{~min}\right)$ and (b) at a series of laser power densities ( $27 \mathrm{ppm}, 15 \mathrm{~min}$ ). (c) Photothermal effect of $\mathrm{Zn}_{4}-\mathrm{H}_{2} \mathrm{Pc} / \mathrm{DP}$ NPs irradiated with a $1064 \mathrm{~nm}$ laser $(27 \mathrm{ppm}, 0.9 \mathrm{~W}$ $\mathrm{cm}^{-2}, 15 \mathrm{~min}$ ); insert: time vs. - $\ln \theta$ during the cooling process. (d) Temperature variations of $\mathrm{Zn}_{4}-\mathrm{H}_{2} \mathrm{Pc} / \mathrm{DP}$ NPs (27 ppm) over seven laser ON/ OFF cycles of $1064 \mathrm{~nm}$ laser irradiation $\left(0.9 \mathrm{~W} \mathrm{~cm}^{-2}, 15 \mathrm{~min}\right.$ ). (e) The temperature change curves of $\mathrm{Zn}_{4}-\mathrm{H}_{2} \mathrm{Pc} / \mathrm{DP} \mathrm{NPs}$ solutions (81 ppm) covered with chicken breast muscles of varying thickness $\left(0,1\right.$, and $4 \mathrm{~mm}$ ) under $1064 \mathrm{~nm}$ laser irradiation (1.0 W cm $\left.{ }^{-2}, 6 \mathrm{~min}\right)$. (f) Photoacoustic spectra of $\mathrm{Zn}_{4}-\mathrm{H}_{2} \mathrm{Pc} / \mathrm{DP}$ NPs in water at various concentrations (dashed line: vis-NIR absorption spectrum of $\mathrm{Zn}_{4}-\mathrm{H}_{2} \mathrm{Pc} / \mathrm{DP} \mathrm{NPs}$ ). 
$\mathrm{H}_{2} \mathrm{Pc} / \mathrm{DP}$ NPs from 9 to $300 \mathrm{ppm}$. Accordingly PA imaging with NIR-II light has an advantage in both the imaging depth and spatial resolution over the NIR-I light. ${ }^{23}$ It is noteworthy that the PA spectrum profile resembles the absorption one (Fig. 1f) of $\mathrm{Zn}_{4}-\mathrm{H}_{2} \mathrm{Pc} / \mathrm{DP} \mathrm{NPs}$, suggesting that the PA signal would be further intensified if the $1048 \mathrm{~nm}$ light was employed to excite, since $\mathrm{Zn}_{4}-\mathrm{H}_{2} \mathrm{Pc} / \mathrm{DP}$ NPs show a higher extinction coefficient at this point than that at $900 \mathrm{~nm}$. This implies the good potential of $\mathrm{Zn}_{4}-\mathrm{H}_{2} \mathrm{Pc} / \mathrm{DP}$ NPs for ideally NIR-II PA imaging application. For further investigation via in vivo PA imaging, $\mathrm{Zn}_{4}-\mathrm{H}_{2} \mathrm{Pc} / \mathrm{DP}$ NPs (600 ppm, $50 \mu \mathrm{L})$ were intratumorally injected into an MCF7 tumor-bearing nude mouse and imaged by PA imaging at various time points after injection. As shown in Fig. S1, $\dagger$ an intense PA signal was observed in the tumor region after being injected with $\mathrm{Zn}_{4}-\mathrm{H}_{2} \mathrm{Pc} / \mathrm{DP}$ NPs and was about ten-fold stronger than that before NP injection at a wavelength of $900 \mathrm{~nm}$ and reached maximum accumulation after $4 \mathrm{~h}$, indicating the biocompatibility and physiological stability of $\mathrm{Zn}_{4}-\mathrm{H}_{2} \mathrm{Pc} / \mathrm{DP}$ NPs. The high photothermal performance, excellent photostability, good penetration depth, and intensive PA signal of $\mathrm{Zn}_{4}-\mathrm{H}_{2} \mathrm{Pc} / \mathrm{DP}$ NPs make them an encouraging PA imagingguided PTA for photothermal therapy in the NIR-II window.

\section{Electronic structure and energy transfer}

In order to clarify the molecular and electronic structures of $\mathrm{Zn}_{4}-$ $\mathrm{H}_{2}\left[\mathrm{Pc}\left(\mathrm{OC}_{12} \mathrm{H}_{17}\right)_{24}\right]$ (1), density functional theory (DFT) calculation was carried out at the level of M06L/6-31G(d). ${ }^{24}$ According to the optimized structure, compound $\mathbf{1}$ employs a saddle curved conformation with an opening angle of $\sim 160^{\circ}$, Fig. 2 a, as a cooperative result of three forces including (1) the co-planar tendency induced by the supra-conjugating behavior between the neighbouring fused phthalocyanine units, (2) the bending tendency due to the obvious steric hindrance between the peripheral substituents, and (3) the resistance to the excessive bending tendency because of the linking locks via the powerful multihydrogen bonds between the solvent $\mathrm{CH}_{2} \mathrm{Cl}_{2}$ and peripheral $-\mathrm{OC}_{12} \mathrm{H}_{17}$ groups, Fig. 2b. As can be found in Fig. 2c, when the supra-macrocycle of $\mathrm{Zn}_{4}-\mathrm{H}_{2}\left[\mathrm{Pc}\left(\mathrm{OC}_{12} \mathrm{H}_{17}\right)_{24}\right]$ (1) is viewed as the fusion between the peripheral $\mathrm{ZnPc}^{*}$ units and the central $\mathrm{H}_{2} \mathrm{Pc}^{*}$ core, the four original $\operatorname{HOMOS}\left(\mathrm{ZnPc}^{*}\right)$ and one original $\mathrm{HOMO}\left(\mathrm{H}_{2} \mathrm{Pc}^{*}\right)$ are coupled into five new frontier occupied orbitals with the energy level between -4.36 and $-4.16 \mathrm{eV}$, meanwhile the eight original LUMOs( $\left.\mathrm{ZnPc}^{*}\right)$ and two original LUMOs $\left(\mathrm{H}_{2} \mathrm{Pc}^{*}\right)$ are coupled into ten new empty orbitals with the energy level between -2.96 and $-2.54 \mathrm{eV}$, leading to the decreased LUMO-HOMO $\left(\mathrm{Zn}_{4}-\right.$ $\mathrm{H}_{2} \mathrm{Pc}$ ) gap of $1.20 \mathrm{eV}$ for 1 . According to the time-dependent density functional theory (TDDFT) calculation results, the $\mathrm{Q}$ band of $\mathrm{Zn}_{4}-\mathrm{H}_{2}\left[\mathrm{Pc}\left(\mathrm{OC}_{12} \mathrm{H}_{17}\right)_{24}\right]$ (1) located in the range of 1000-1100 nm is assigned mainly to the coupled transitions including $\mathrm{HOMO} \rightarrow$ LUMO (88\%), HOMO-1 $\rightarrow$ LUMO+1 (8\%), and HOMO-4 $\rightarrow$ $\mathrm{LUMO}+2(3 \%)$.

It is well known that when a molecule is excited by a photon, there are three possible pathways to release energy within the high-energy state including (1) the emission of photons (known as fluorescence or phosphorescence), (2) the nonradiative process (generating heat), and (3) the exit from the singlet state (S1) to the triplet state (T1) via spin-inversion, which is responsible for the generation of singlet oxygen. ${ }^{5}$ For the present $\mathrm{Zn}_{4}-\mathrm{H}_{2}\left[\mathrm{Pc}\left(\mathrm{OC}_{12} \mathrm{H}_{17}\right)_{24}\right]$ (1) molecule, Fig. 2d, there is a slight entropy increment of $\sim 30 \mathrm{~J} \mathrm{~mol}^{-1} \mathrm{~K}^{-1}$ in the manner of releasing a new photon with an energy of $1.15 \mathrm{eV}(1081 \mathrm{~nm})$, whereas there is a strong entropy increment of $311.1 \mathrm{~J} \mathrm{~mol}^{-1}$ $\mathrm{K}^{-1}$ for the nonradiative process to convert the excitation energy into thermal vibrations. As a consequence, the nonradiative process should be surely the preferred pathway for the molecule of 1 to release energy after being excited. According to the
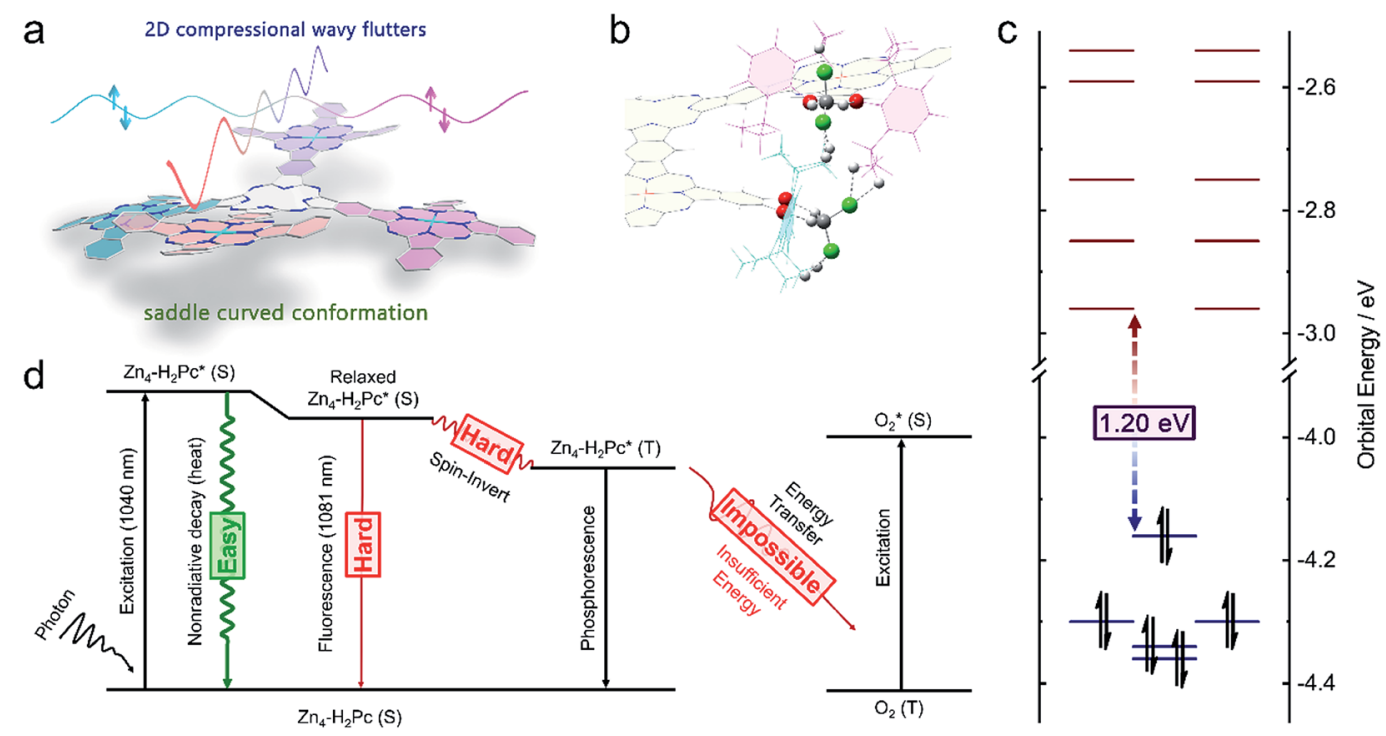

Fig. 2 (a) Molecular structure of $\mathrm{Zn}_{4}-\mathrm{H}_{2}\left[\mathrm{Pc}\left(\mathrm{OC}_{12} \mathrm{H}_{17}\right)_{24}\right]$ (1) optimized on the basis of DFT calculations with all the hydrogen atoms and substituents omitted for clarity. (b) Non-covalent interactions between the solvent molecules and the peripheral $-\mathrm{OC}_{12} \mathrm{H}_{17} \mathrm{groups}$ (c) The occupied frontier orbitals of 1 coupled by corresponding orbitals of the peripheral ZnPc* unit and the central $\mathrm{H}_{2} \mathrm{Pc} * \mathrm{core}_{\text {. }}(\mathrm{d}) \mathrm{Schematic} \mathrm{Jablonski}$ diagram representing different energy transfer pathways. 
calculation result, the significant compressional wave fluttering, a smooth nonradiative energy-dissipation pathway for twodimensional conjugated materials, ${ }^{20}$ with vibrational energies of $798 \mathrm{~cm}^{-1}$ (98.9 meV), $914 \mathrm{~cm}^{-1}(113.7 \mathrm{meV})$, and $1003 \mathrm{~cm}^{-1}$ (124.7 meV) over the broad $\mathrm{Zn}_{4}-\mathrm{H}_{2}\left[\mathrm{Pc}\left(\mathrm{OC}_{12} \mathrm{H}_{17}\right)_{24}\right]$ (1) conjugated framework, together with the peripheral rotating substituents, which just provides a smooth way to nonradiatively release the excitation energy, is able to nearly completely prevent the radiative energy-releasing manners including fluorescence and phosphorescence. This in turn becomes responsible for the very low fluorescence quantum yield of $\sim 3 \%$ for 1 as detailed above. On the other hand, an energy of $0.98 \mathrm{eV}(1262 \mathrm{~nm})$ is required for the reaction of $\mathrm{O}_{2}$ (triplet) $\rightarrow \mathrm{O}_{2}$ (singlet), ${ }^{25,26}$ which however cannot be afforded by $\mathrm{Zn}_{4}-\mathrm{H}_{2}\left[\mathrm{Pc}\left(\mathrm{OC}_{12} \mathrm{H}_{17}\right)_{24}\right]$ at the $\mathrm{T} 1$ state with an excitation energy of $0.95 \mathrm{eV}(1305 \mathrm{~nm})$.

In addition, according to previous reports, highly ordered molecular stacking within the nanostructure can promote a nonradiative relaxation process by quenching fluorescence and reactive oxygen species. ${ }^{21,25,27}$ This is also true for the present case. When the $\mathrm{Zn}_{4}-\mathrm{H}_{2}\left[\mathrm{Pc}\left(\mathrm{OC}_{12} \mathrm{H}_{17}\right)_{24}\right]$ (1) molecules are assembled into nanoparticles, a new thermal vibrational model is introduced by the inter-molecular interactions. As can be seen in Fig. S14, $\uparrow$ the easily occurring breathing between the adjacent van der Waals binding molecules is just at the energy level between 133 and $483 \mathrm{~cm}^{-1}$ (13-48 meV, depending on the binding manner), which also provides a new energy-dissipation pathway, leading to a further reduced fluorescence quantum yield of $\sim 2 \%$ in the region of 1050-1150 $\mathrm{nm}$ for the assembled nanostructure of 1 . In other words, both the intra-molecular compressional wave fluttering and rotational motions of $\mathbf{1}$ as well as the inter-molecular breathing vibrations in the nanostructure of 1 provide much easier energy-dissipation pathways in comparison with the fluorescence-releasing pathway, resulting in $\sim 998 \%$ energy-loss by means of the nonradiative process (the high entropy production manner) and only $\sim 2 \%$ energyloss through the fluorescence process (the low entropy production manner) in the $\mathrm{Zn}_{4}-\mathrm{H}_{2} \mathrm{Pc} / \mathrm{DP}$ NPs. This in turn leads to nearly vanished fluorescence and fully-utilized NIR-II energy, rendering the $\mathrm{Zn}_{4}-\mathrm{H}_{2} \mathrm{Pc} / \mathrm{DP}$ NPs a new molecular material-based PTA for effective NIR-II window photothermal therapy.

\section{Cytotoxicity and photothermal therapy in vitro}

The photothermal cytotoxicity of $\mathrm{Zn}_{4}-\mathrm{H}_{2} \mathrm{Pc} / \mathrm{DP}$ NPs was investigated via standard cell viability methylthiazoltetrazolium bromide (MTT) assays. After being incubated with $\mathrm{Zn}_{4}-\mathrm{H}_{2} \mathrm{Pc} / \mathrm{DP}$ NPs at various concentrations from 0 to $250 \mathrm{ppm}$ for $24 \mathrm{~h}, \mathrm{MCF}-$ 7 cells showed no discernible cytotoxicity and remained $\sim 95 \%$ viable even at the $\mathrm{Zn}_{4}-\mathrm{H}_{2} \mathrm{Pc} / \mathrm{DP} \mathrm{NP}$ concentration of $250 \mathrm{ppm}$, Fig. 3a. In contrast, after exposure to the $1064 \mathrm{~nm}$ laser for 1 $\min \left(1.5 \mathrm{~W} \mathrm{~cm}^{-2}\right)$, the viability of cells was significantly decreased with the increasing $\mathrm{Zn}_{4}-\mathrm{H}_{2} \mathrm{Pc} / \mathrm{DP} \mathrm{NP}$ concentration, leading to an IC50 value of $74 \mathrm{ppm}$ and revealing the origin of the cytotoxicity from the PTT effect. Furthermore, confocal laser scanning microscopy (CLSM) images of MCF-7 cells co-stained with green-emissive calcine AM and red-emissive propidium iodide (PI) were obtained after incubation with or without 250 ppm $\mathrm{Zn}_{4}-\mathrm{H}_{2} \mathrm{Pc} / \mathrm{DP}$ NPs. As shown in Fig. $3 \mathrm{~b}$ and $\mathrm{S15}, \dagger$ green fluorescence was observed for cells that are treated either with laser irradiation only or with $\mathrm{Zn}_{4}-\mathrm{H}_{2} \mathrm{Pc}$ /DP NPs in the dark only, indicating the lack of influence of $1064 \mathrm{~nm}$ laser irradiation alone on the viability of MCF-7 cells and the biocompatibility of the $\mathrm{Zn}_{4}-\mathrm{H}_{2} \mathrm{Pc} / \mathrm{DP}$ NPs. On the other hand, red fluorescence was obviously imaged for the cells treated with "NPs + laser", agreeing well with the result of the MTT assay as detailed above, revealing the significant photothermal ablation effect of $\mathrm{Zn}_{4^{-}}$ $\mathrm{H}_{2} \mathrm{Pc} / \mathrm{DP}$ NPs on MCF-7 cells.

\section{Photothermal therapy in vivo}

Encouraged by all the above-mentioned results, $\mathrm{Zn}_{4}-\mathrm{H}_{2} \mathrm{Pc} / \mathrm{DP}$ NPs' in vivo photothermal therapy on MCF-7 tumor-bearing nude mice was further evaluated. The mice were randomly divided into two groups (five mice per group): the group treated with the 1064 $\mathrm{nm}$ laser alone (control group) and the one treated with the combination of $\mathrm{Zn}_{4}-\mathrm{H}_{2} \mathrm{Pc} / \mathrm{DP}$ NPs and the $1064 \mathrm{~nm}$ laser (NP Group). The change in temperature was monitored using an IR thermal camera during laser irradiation. After $4 \mathrm{~h}$ post injection, Fig. $4 \mathrm{a}$ and $\mathrm{b}$, the tumors with intratumoral injection of $\mathrm{Zn}_{4}-\mathrm{H}_{2} \mathrm{Pc}$ / DP NPs (600 ppm, $50 \mu \mathrm{L}$ per mouse) showed a rapid increase in temperature (from 36.2 to $62.6{ }^{\circ} \mathrm{C}$ after $90 \mathrm{~s}$ and finally stabilizes at $\sim 62{ }^{\circ} \mathrm{C}$ ) when exposed to the $1064 \mathrm{~nm}$ laser at $0.6 \mathrm{~W} \mathrm{~cm}^{-2}$ for $10 \mathrm{~min}$, whereas a slight change in temperature (less than $6^{\circ} \mathrm{C}$ ) of tumor sites was observed for the control group under the same
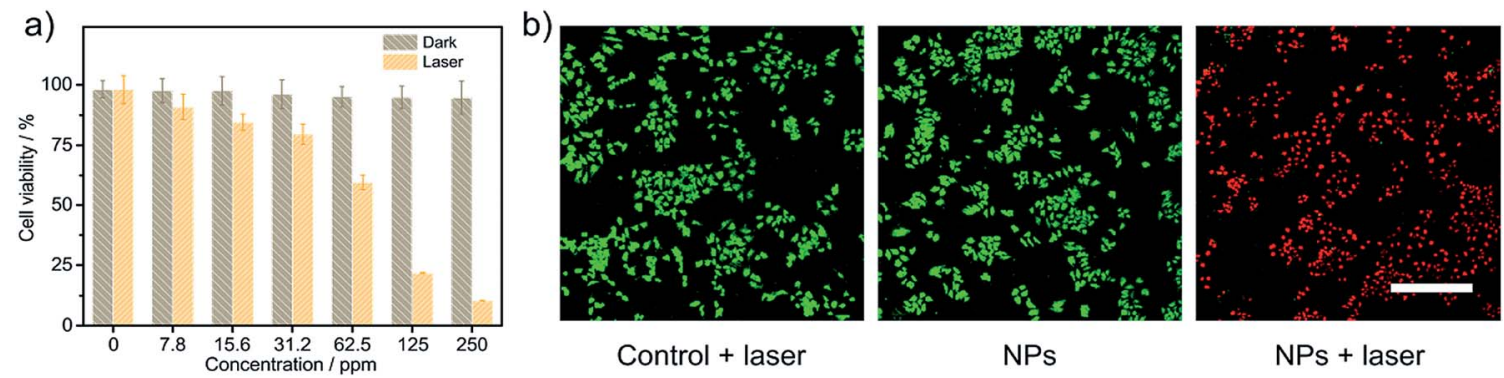

Fig. 3 (a) Relative cell viabilities of MCF-7 cells under incubation of $\mathrm{Zn}_{4}-\mathrm{H}_{2} \mathrm{Pc} / \mathrm{DP}$ NPs at various concentrations $(n=6)$ without or with 1064 nm laser irradiation (1.5 W cm $\mathrm{W}^{-2}, 1 \mathrm{~min}$ ). (b) CLSM images of MCF-7 cells stained with calcein AM and propidium iodide (dead cells, red) after incubation without or with $250 \mathrm{ppm} \mathrm{Zn}_{4}-\mathrm{H}_{2} \mathrm{Pc} / \mathrm{DP}$ NPs for $4 \mathrm{~h}$ irradiated with a $1064 \mathrm{~nm}$ laser $\left(1.2 \mathrm{~W} \mathrm{~cm}^{-2}, 3\right.$ min). Images share the same scale $\operatorname{bar}(200 \mu \mathrm{M})$. 

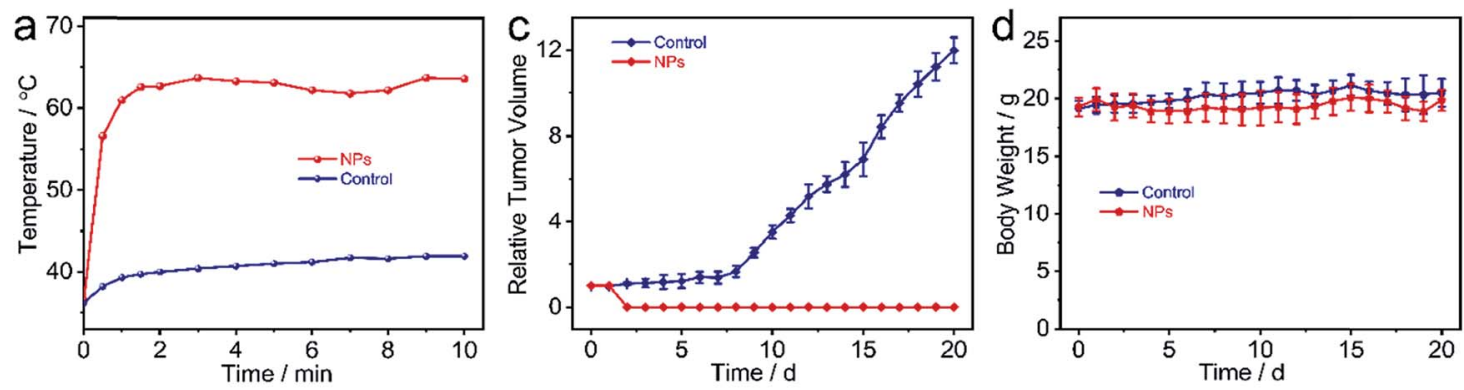

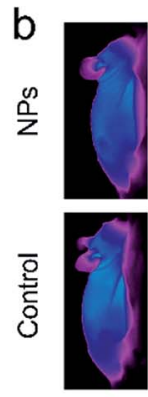

0

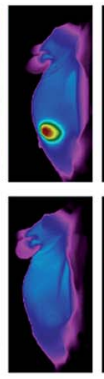

0.5

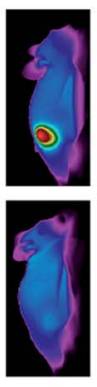

1

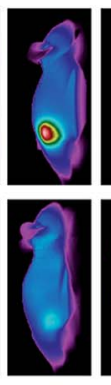

3

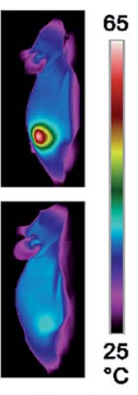

$10 \mathrm{~min}$ e
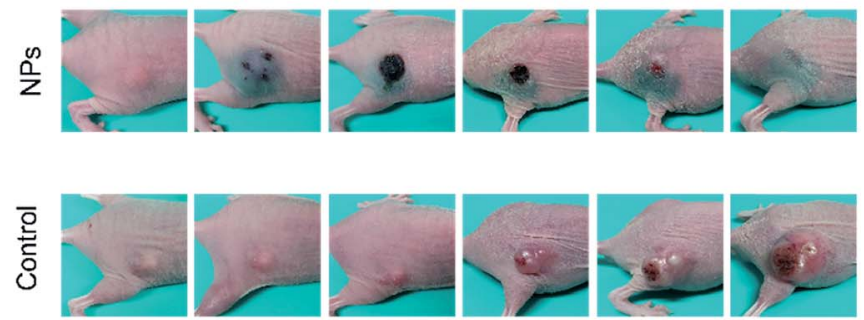

0

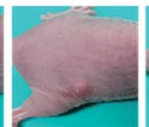

3

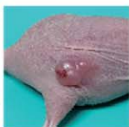

7

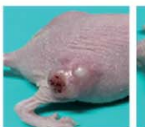

12

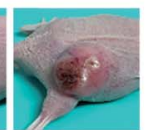

20 day

Fig. 4 (a) Temperature elevation of the tumor region in MCF-7 tumor-bearing mice under 1064 nm laser irradiation at a power density of $0.6 \mathrm{~W}$ $\mathrm{cm}^{-2}$ for $10 \mathrm{~min}$ with or without the assistance of intratumoral injection of $\mathrm{Zn}_{4}-\mathrm{H}_{2} \mathrm{Pc} / \mathrm{DP} \mathrm{NPs}$. (b) Corresponding IR thermal images of mice under irradiation at varied time intervals $(0,0.5,1,3$, and $10 \mathrm{~min})$. (c) Tumor growth curves and (d) body-weight curves of mice in control and NP groups after treatment $(n=5)$. (e) Digital photos of mice before and after treatment at varied time intervals $(0,1,3,7,12$, and 20 day).

conditions, indicating the excellent photothermal effect of $\mathrm{Zn}_{4^{-}}$ $\mathrm{H}_{2} \mathrm{Pc} /$ DP NPs. Moreover, the tumor sizes and body weights of each mouse were monitored during the subsequent 20 days, Fig. $4 \mathrm{c}$ and d. Distinguishably, tumors in mice injected with $\mathrm{Zn}_{4}-\mathrm{H}_{2} \mathrm{Pc} / \mathrm{DP}$ NPs were eliminated after $1064 \mathrm{~nm}$ laser irradiation, leaving burn scars at the original tumor sites on the 2nd day after treatment, which fell off after about two weeks, and no tumor recurrence was observed. In good contrast, tumors in the control group treated with irradiation only showed an obvious growth rate, Fig. 4e and S16. $\dagger$ Moreover, all the mice showed negligible weight fluctuation during the observation period, indicating the biocompatibility of $\mathrm{Zn}_{4}-\mathrm{H}_{2} \mathrm{Pc} / \mathrm{DP}$ NPs during the PTT treatment. Hematoxylin and eosin (H\&E) staining shows no obvious histopathological damage in major organs from the mouse treated with $\mathrm{Zn}_{4}-\mathrm{H}_{2} \mathrm{Pc} / \mathrm{DP}$ NPs and irradiation, Fig. S17. $\dagger$ As a result, in vivo treatment experimental results also disclose the efficiency and biocompatibility of $\mathrm{Zn}_{4}-\mathrm{H}_{2} \mathrm{Pc} / \mathrm{DP}$ NPs for PTT in the second NIR window, in line with the in vitro experimental result.

\section{Conclusions}

In conclusion, we for the first time demonstrated a molecular material-based PTA for high-performance tumor ablation in the second NIR window. Associated with the intrinsic spectroscopic nature of the single molecular compound, $\mathrm{Zn}_{4}-\mathrm{H}_{2} \mathrm{Pc} / \mathrm{DP}$ NPs possess a strong NIR absorption, excellent stability against dilution and irradiation, high photothermal conversion efficiency $(58.3 \%)$ at $1064 \mathrm{~nm}$, and an intense photoacoustic signal, which facilitates the application for NIR-II window PA imagingguided PTT. Both in vitro and in vivo photothermal studies demonstrate the excellence of $\mathrm{Zn}_{4}-\mathrm{H}_{2} \mathrm{Pc} / \mathrm{DP}$ NPs as a PTA for photothermal ablation of tumor cells together with high biocompatibility. The present result not only promises the great potential of $\mathrm{Zn}_{4}-\mathrm{H}_{2} \mathrm{Pc} / \mathrm{DP}$ NPs as a novel photothermal and photoacoustic contrast agent for tumor therapy, but also provides a new strategy towards enhancing the photothermal conversional efficiency of molecular material-based PTAs in the NIR-II window by depending on the significant two-dimensional compressional wave fluttering.

\section{Conflicts of interest}

There are no conflicts to declare.

\section{Acknowledgements}

All animal procedures were performed in accordance with the Guidelines for Care and Use of Laboratory Animals of Institute of Process Engineering, Chinese Academy of Sciences and approved by the Animal Ethics Committee of Beijing. Financial support from the Natural Science Foundation of China (No. 21631003, 21671017, and 21871024), the Fundamental Research Funds for the Central Universities (No. FRF-BD-17016A), and University of Science and Technology Beijing is gratefully acknowledged.

\section{Notes and references}

1 P. Liang, Q. Tang, Y. Cai, G. Liu, W. Si, J. Shao, W. Huang, Q. Zhang and X. Dong, Chem. Sci., 2017, 8, 7457-7463. 
2 X. Liang, Y. Li, X. Li, L. Jing, Z. Deng, X. Yue, C. Li and Z. Dai, Adv. Funct. Mater., 2015, 25, 1451-1462.

3 L. Cheng, C. Wang, L. Feng, K. Yang and Z. Liu, Chem. Rev., 2014, 114, 10869-10939.

4 Z. Zha, X. Yue, Q. Ren and Z. Dai, Adv. Mater., 2013, 25, 777782.

5 Y. Liu, P. Bhattarai, Z. Dai, et al., Chem. Soc. Rev., 2019, 48(7), 2053-2108.

6 C. Yin, G. Wen, C. Liu, B. Yang, S. Lin, J. Huang, P. Zhao, S. H. D. Wong, K. Zhang and X. Chen, ACS Nano, 2018, 12, 12201-12211.

7 X. Han, J. Huang, X. Jing, D. Yang, H. Lin, Z. Wang, P. Li and Y. Chen, ACS Nano, 2018, 12, 4545-4555.

8 N. Yu, C. Peng, Z. Wang, Z. Liu, B. Zhu, Z. Yi, M. Zhu, X. Liu and Z. Chen, Nanoscale, 2018, 10, 2542-2554.

9 H. Lin, S. Gao, C. Dai, Y. Chen and J. Shi, J. Am. Chem. Soc., 2017, 139, 16235-16247.

10 B. Guo, Z. Sheng, D. Hu, C. Liu, H. Zheng and B. Liu, Adv. Mater., 2018, 30, 1802591.

11 Y. Jiang, J. Li, X. Zhen, C. Xie and K. Pu, Adv. Mater., 2018, 30, 1705980.

12 T. Sun, J.-H. Dou, S. Liu, X. Wang, X. Zheng, Y. Wang, J. Pei and Z. Xie, ACS Appl. Mater. Interfaces, 2018, 10, 7919-7926.

13 S. Singh, A. Aggarwal, N. D. K. Bhupathiraju, G. Arianna, K. Tiwari and C. M. Drain, Chem. Rev., 2015, 115, 1026110306.

14 X. Li, C.-y. Kim, S. Lee, D. Lee, H.-M. Chung, G. Kim, S.-H. Heo, C. Kim, K.-S. Hong and J. Yoon, J. Am. Chem. Soc., 2017, 139, 10880-10886.
15 L. Du, H. Qin, T. Ma, T. Zhang and D. Xing, ACS Nano, 2017, 11, 8930-8943.

16 S. Makarov, C. Litwinski, E. A. Ermilov, O. Suvorova, B. Röder and D. Wöhrle, Chem.-Eur. J., 2006, 12, 1468-1474.

17 S. G. Makarov, O. N. Suvorova, C. Litwinski, E. A. Ermilov, B. Röder, O. Tsaryova, T. Dülcks and D. Wöhrle, Eur. J. Inorg. Chem., 2007, 2007, 546-552.

18 X. Li, X.-H. Peng, B.-D. Zheng, J. Tang, Y. Zhao, B.-Y. Zheng, M.-R. Ke and J.-D. Huang, Chem. Sci., 2018, 9, 2098-2104.

19 K. K. Ng and G. Zheng, Chem. Rev., 2015, 115, 11012-11042.

20 T. R. Nelson, D. Ondarse-Alvarez, N. Oldani, B. RodriguezHernandez, L. Alfonso-Hernandez, J. F. Galindo, V. D. Kleiman, S. Fernandez-Alberti, A. E. Roitberg and S. Tretiak, Nat. Commun., 2018, 9, 2316.

21 Q. Zou, M. Abbas, L. Zhao, S. Li, G. Shen and X. Yan, J. Am. Chem. Soc., 2017, 139, 1921-1927.

22 Q. Tian, F. Jiang, R. Zou, Q. Liu, Z. Chen, M. Zhu, S. Yang, J. Wang, J. Wang and J. Hu, ACS Nano, 2011, 5, 9761-9771. 23 Q. Miao and K. Pu, Adv. Mater., 2018, 30, 1801778.

24 Y. Zhao and D. G. Truhlar, J. Chem. Phys., 2006, 125, 194101. 25 Y. Deng, L. Huang, H. Yang, H. Ke, H. He, Z. Guo, T. Yang, A. Zhu, H. Wu and H. Chen, Small, 2017, 13, 1602747.

26 F. Würthner, T. E. Kaiser and C. R. Saha-Möller, Angew. Chem., Int. Ed., 2011, 50, 3376-3410.

27 L. Zhao, Y. Liu, R. Chang, R. Xing and X. Yan, Adv. Funct. Mater., 2019, 29, 1806877. 